\section{CIHR appointment}

Appointing a representative from the drug industry to the Canadian Institutes of Health Research (CIHR) governing council ${ }^{1}$, and particularly a representative from Pfizer, seems inappropriate given that industry's, and that company's, recent history of illegalities in marketing products. ${ }^{2} \mathrm{CIHR}$ has recently been given responsibility for setting up Canada's first Drug Safety and Effectiveness Network. CIHR will identify and fund university-based researchers to evaluate pharmaceuticals after they come to market. This effort is designed to gather evidence at arm's-length from drug companies and also at arm's length from government - with a commitment that the evidence on safety and effectiveness will not remain confidential. Designing these evaluations cannot be done in partnership with the companies that market the drugs. Experience teaches us that this results in benefits being overstated and risks being downplayed. The CIHR governing council is no place for narrow interest groups.

\section{Noralou P. Roos, professor \\ Patricia Baird, professor emeritus \\ Faculty of Medicine, University of \\ Manitoba, Winnipeg, Man.}

\section{REFERENCES}

1. Silversides A. CIHR appointment stirs controversy. CMAJ 2009; 181:E256-57.

2. Silversides A. Federal committee to review Pfizer v-p appointment to CIHR council. CMAJ 2009; Nov. 9. [E-pub ahead of print]

For the full letter, go to: www.cmaj.ca/cgi/eletters /181/11/E256\#245405

DOI:10.1503/cmaj.110-2002

\section{Child pedestrians}

The CMAJ review on child injuries and the built environment by Andrew Howard ${ }^{1}$ is a valuable contribution to the literature. However, the review ignores developing countries, where more fatal child pedestrian injuries occur on a daily basis than in most industrialized countries. Research shows that economic factors may play a role in the higher inci- dence of child pedestrian crashes in developing countries, because many of the children injured were engaged in buying and selling goods along the roadsides. ${ }^{2}$ We also need to recognize that, apart from other pedestrian-related risk factors, vulnerable children in underdeveloped countries are victims of poor design features of vehicles. These vehicles are made in and for industrialized countries, and do not take the unique traffic situations in developing countries into consideration. Now is the time to incorporate effective technology and materials that could reduce the impact of motor vehicle crashes on child, and all, pedestrians.

\section{Ediriweera Desapriya}

Department of Pediatrics, Faculty of Medicine, University of British Columbia, Vancouver, BC

\section{REFERENCES}

1. Howard AW. Keeping children safe: rethinking how we design our surroundings CMAJ 2009; Oct. 5. [E-pub ahead of print]

2. Adesunkanmi ARK, Oginni LM, Oyelami OA Road traffic accidents to African children: assessment of severity using the injury severity score (ISS). Injury 2000;31:225-8.

For the full letter, go to: www.cmaj.ca/cgi/eletters /cmaj.080162v1\#216262

DOI:10.1503/cmaj.109-2043

\section{Correction: Review}

In the article "Management of asthma in adults," published Dec. 8, the dose equivalences for beclomethasone dipropionate (hydrofluoralkane; HFA) and ciclesonide in Table 2 were incorrect. For beclomethasone (HFA) the daily doses should have been listed as 100 $250 \mu \mathrm{g}$ for low, $>250-500 \mu \mathrm{g}$ for medium and $>500-1000 \mu \mathrm{g}$ for high doses. For ciclesonide, the daily doses should have been listed as 100-200 $\mu \mathrm{g}$ for low, $>200-400 \mu \mathrm{g}$ for medium and $>400-1600 \mu \mathrm{g}$ for high doses. Also, in the section of the article "The case continued," the list of low-dose inhaled corticosteroids in the fourth bullet should have included beclomethasone dipropionate $100 \mu \mathrm{g}$ one inhalation twice daily. The article has been corrected online.

\section{REFERENCE}

1. Balter MS, Bell AD, Kaplan AG, et al. Management of asthma in adults. CMAJ 2009;181:915-22.

DOI:10.1503/cmaj.110-2008

\section{Correction: Research}

In Table 4 of a Sept. 15 article on home births, ${ }^{1}$ the headings for the two columns on planned home births ("Planned home birth with midwife v. planned hospital birth with midwife" and "Planned home birth with midwife v. planned hospital birth with physician") were reversed.

\section{REFERENCE}

1. Janssen PA, Saxell L, Page LA, et al. Outcomes of planned home birth with registered midwife versus planned hospital birth with midwife or physician. CMAJ 2009;181(6-7):377-83.

DOI:10.1503/cmaj.110-2011

\section{Correction: Salon}

The article "End of life, year after year after year," published Nov. 24, said cosmologist Stephen Hawking died in 2009. In fact, Hawking is still alive. The article also incorrectly spelled Hawking's first name. The CMAJ apologizes for these errors.

\section{REFERENCE}

1. Koch T. End of life, year after year after year CMAJ 2009; 181:868.

DOI:10.1503/cmaj.110-2009

\section{Letters to the editor}

In submitting a letter, you automatically consent to have it appear online and/or in print. All letters accepted for print will be edited by $C M A J$ for space and style. Most references and multiple authors' names and full affiliations will appear online only. (The full version of any letter accepted for print will be posted at cmaj.ca.) 